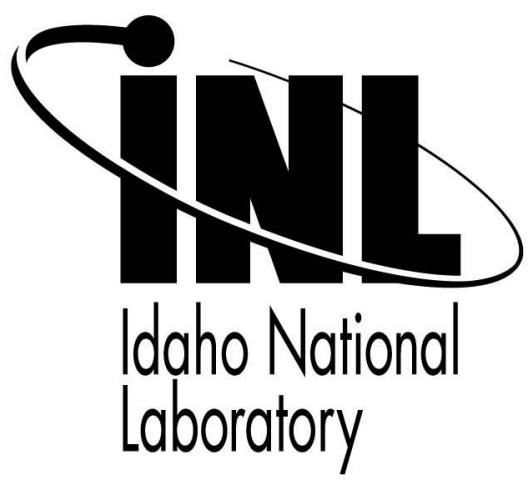

\title{
Measurement of Flow Phenomena in a Lower Plenum Model of a Prismatic Gas-Cooled Reactor
}

ICONE 16

Hugh M. Mcllroy, Jr. Donald M. McEligot Robert J. Pink

May 2008

This is a preprint of a paper intended for publication in a journal or proceedings. Since changes may be made before publication, this preprint should not be cited or reproduced without permission of the author. This document was prepared as an account of work sponsored by an agency of the United States Government. Neither the United States Government nor any agency thereof, or any of their employees, makes any warranty, expressed or implied, or assumes any legal liability or responsibility for any third party's use, or the results of such use, of any information, apparatus, product or process disclosed in this report, or represents that its use by such third party would not infringe privately owned rights. The views expressed in this paper are not necessarily those of the United States Government or the sponsoring agency. 


\section{MEASUREMENT OF FLOW PHENOMENA IN A LOWER PLENUM MODEL OF A PRISMATIC GAS-COOLED REACTOR}

\author{
Hugh M. Mcllroy Jr. \\ Idaho National Laboratory \\ P.O. Box 1625 \\ Idaho Falls, Idaho 83415
}

\author{
Donald M. McEligot* \\ Idaho National Laboratory \\ P.O. Box 1625 \\ Idaho Falls, Idaho 83415-3885
}

\author{
Robert J. Pink \\ Idaho National Laboratory \\ P.O. Box 1625 \\ Idaho Falls, Idaho 83415
}

\section{ABSTRACT}

Mean-velocity-field and turbulence data are presented that measure turbulent flow phenomena in an approximately 1:7 scale model of a region of the lower plenum of a typical prismatic gas-cooled reactor (GCR) similar to a General Atomics Gas-Turbine-Modular Helium Reactor (GTMHR) design. The data were obtained in the Matched-Index-ofRefraction (MIR) facility at Idaho National Laboratory (INL) and are offered for assessing computational fluid dynamics (CFD) software. This experiment has been selected as the first Standard Problem endorsed by the Generation IV International Forum.

Results concentrate on the region of the lower plenum near its far reflector wall (away from the outlet duct). The flow in the lower plenum consists of multiple jets injected into a confined cross flow - with obstructions. The model consists of a row of full circular posts along its centerline with half-posts on the two parallel walls to approximate geometry scaled to that expected from the staggered parallel rows of posts in the reactor design. The model is fabricated from clear, fused quartz to match the refractive-index of the working fluid so that optical techniques may be employed for the measurements. The benefit of the MIR technique is that it permits optical measurements to determine flow characteristics in complex passages in and around objects to be obtained without locating intrusive transducers that will disturb the flow field and without distortion of the optical paths. An advantage of the INL system
\end{abstract}

is its large size, leading to improved spatial and temporal resolution compared to similar facilities at smaller scales. A three-dimensional (3-D) Particle Image Velocimetry (PIV) system was used to collect the data. Inlet jet Reynolds numbers (based on the jet diameter and the time-mean bulk velocity) are approximately 4,300 and 12,400. Uncertainty analyses and a discussion of the standard problem are included.

The measurements reveal developing, non-uniform, turbulent flow in the inlet jets and complicated flow patterns in the model lower plenum. Data include three-dimensional vector plots, data displays along the coordinate planes (slices) and presentations that describe the component flows at specific regions in the model. Information on inlet conditions is also presented.

\section{INTRODUCTION}

The Very High Temperature Reactor (VHTR) is the most likely candidate for the Next Generation Nuclear Plant (NGNP). Because of the high temperatures characteristic of the VHTR, it is important to be able to simulate the turbulent flow in the reactor, especially in the lower plenum in order to ensure that large temperature gradients are not present in the coolant that could adversely impact structural materials. It is recognized that to simulate the flow in the VHTR lower plenum, advanced CFD codes using appropriate turbulence modeling will be necessary.

The objectives of the experimental and computational research programs conducted at INL are (1) to build accurate,

\footnotetext{
${ }^{*}$ Professor Emeritus, University of Arizona and presently on sabbatical leave at IKE, University of Stuttgart
} 
reliable numerical simulation models of important VHTR thermal-hydraulic phenomena; (2) to provide benchmark data for the assessment and improvement of thermal-hydraulic codes proposed for evaluating the VHTR designs; and (3) to begin preliminary code development and assessment tasks based on identified modeling needs and existing data.

Feasibility studies for VHTR designs will require accurate, reliable predictions of material temperatures to evaluate the material capabilities. In a prismatic VHTR, these temperatures depend on the thermal convection in the coolant channels for the core and in other important components. Unfortunately, correlations in one-dimensional system codes for gas-cooled reactors typically underpredict these temperatures, particularly in reduced-power operations and hypothesized-accident scenarios. Likewise, some turbulence models in general purpose CFD codes provide optimistic predictions in the sense that surface temperatures are typically underpredicted $[1,2]$. These treatments are further complicated by the nonhomogeneous power distributions with strong peaking that can occur, in addition to buoyancy, strong pressure gradients and gas property variations in the channels (the "hot channel" issue). The U.S. Department of Energy (DOE) needs improved modeling capabilities, independent from the sometimes simplistic approaches employed by reactor vendors. These computational capabilities need, in turn, to be validated by comparison to experimental and analytical benchmark data.

McEligot et al. [3] reported six areas of thermal hydraulic phenomena in which the application of improved CFD and system thermal-hydraulic analytical techniques can be used in the design and safety analyses of a prismatic VHTR. Several of these phenomena are pertinent to pebble bed versions of the VHTR as well. Initial studies concentrate on coolant flow distribution through the reactor core channels and mixing of hot jets in the reactor core lower plenum. These phenomena are important both in normal operation and in accident scenarios. This paper addresses the mixing of hot jets in the lower plenum of the reactor core.

INL has developed a large Matched-Index-of-Refraction (MIR) flow system that uses optical techniques, such as laser Doppler velocimetry (LDV) and PIV, to obtain flow field measurements in complex passages without disturbing the flow. The refractive indices of the fluid and the model are matched so that there is no optical distortion. The large size provides good spatial and temporal resolution and provides a means to measure flow fields, turbulence and mixing in the complex geometry of a prismatic VHTR lower plenum. The resulting data may be employed to assess CFD codes and their turbulence models for the limiting case of dominant forced convection where temperature can be considered to be a passive scalar. A code must be validated against these data before it can be considered for extension to include more complicated phenomena (e.g., buoyancy influences).

The general approach of the overall project is to develop new benchmark experiments for assessment in parallel with CFD and coupled CFD systems code calculations for the same geometry. The velocity and turbulence fields measured in the MIR flow system will be used to assess the capabilities of the CFD codes and their turbulence models and to provide guidance in improving the models. A model of the lower plenum based on the point design of the NGNP [4] was developed and employed in this experiment.

McEligot and McCreery [5] conducted scaling studies and conceptual designs for flow and heat-transfer experiments intended to assess CFD codes and their turbulence models proposed for application to prismatic VHTR concepts. Condie et al. [6] documented the design of the present experiment to measure generic flow phenomena expected to occur in the lower plenum of a typical prismatic VHTR. The product of these efforts resulted in the fabrication and installation of a scaled model of the region of a typical VHTR lower plenum that is near the outer reflector wall away from the plenum outlet.

The objective of this paper is to document the data set that has been established as benchmark data for flow phenomena in a lower plenum model of a typical prismatic gas-cooled reactor for the validation (as defined by Roach [7]) of CFD codes.

\section{MATCHED INDEX-OF-REFRACTION FLOW FACILITY}

Velocity field measurements were taken in the MIR closedloop flow system located at INL in Idaho Falls, Idaho (Fig. 1). Stoots et al. [8] presented a detailed review of this system. The system consists of a stainless steel closed flow loop with three polycarbonate and glass test sections. The facility can operate with water or light mineral oil as the working fluid. The working fluid for this experiment was light mineral oil that is circulated (clockwise in Fig. 1) by an axial pump powered by a $56 \mathrm{~kW}$ (75-hp) variable speed electric motor that can provide a maximum volumetric flow rate of approximately $0.6 \mathrm{~m}^{3} / \mathrm{s}$ of mineral oil through the test section. This maximum volumetric flow rate corresponds to a maximum test section inlet velocity

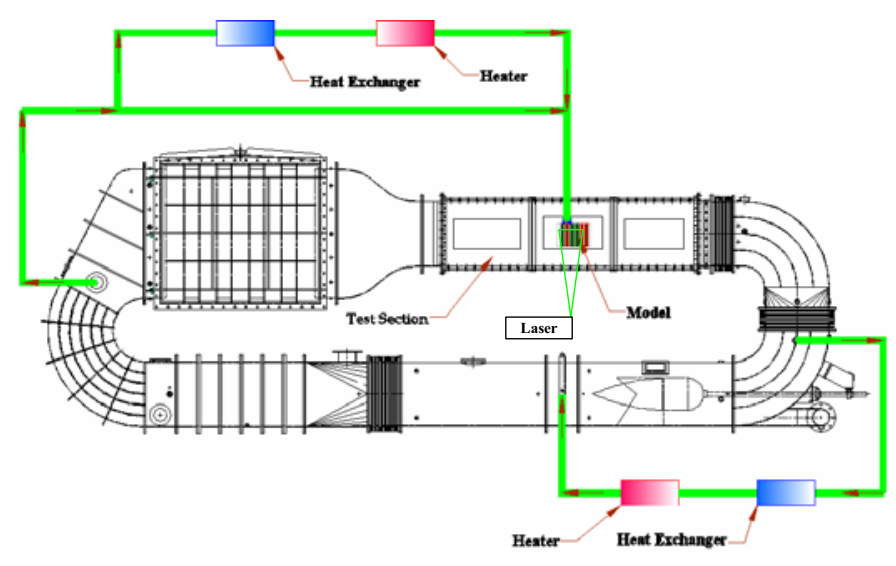

Figure 1. MIR Facility.

of approximately $1.7 \mathrm{~m} / \mathrm{s}$. The test section includes three chambers that are constructed of $3.8 \mathrm{~cm}$ thick polycarbonate supported by a stainless steel framework. Each chamber is fitted with a removable lid. The test section inside dimension is 
$0.61 \mathrm{~m}$ square and it is $2.44 \mathrm{~m}$ long. Both sides of each chamber of the test section are equipped with glass window inserts in the side panels to accommodate high quality measurements with LDV and/or PIV systems.

Mineral oil in the primary flow loop flows around the model for temperature control of the external surfaces of the model. The mineral oil temperature is maintained with a temperature control loop as shown in the lower right corner of Fig. 1. The temperature control loop extracts approximately $300 \mathrm{~L} / \mathrm{min}$ from the primary loop flow and pumped through a glycolcooled heat exchanger and a $10 \mathrm{~kW}$ DC heater, filtered, and then re-injected into the primary flow loop. This temperature control system can maintain the fluid temperature in the test section to within $\pm 0.05{ }^{\circ} \mathrm{C}$ of the specified index-matching temperature. An additional auxiliary flow loop (shown in the upper left corner of Fig. 1), with a similar temperature control system, is used to provide fluid for the interior-model flows. Fluid is extracted from the primary flow loop and routed to a 5 $\mathrm{kW}(7 \mathrm{hp}$ ) pump that produces flow to the model inlet jets. To maintain the required working fluid temperature, a portion of this fluid is extracted from the auxiliary loop and routed through a parallel auxiliary temperature control loop. As in the primary temperature control loop, the mineral oil is cooled and reheated before returning to the auxiliary flow loop and into the model inlet jets. Control instrumentation includes thermistors, flow meters, data acquisition, and computer controls.

\section{PARTICLE IMAGE VELOCIMETRY (PIV) SYSTEM}

Velocity field measurements were obtained with a 3-D PIV system from LaVision, Inc ${ }^{*}$. The 3-D PIV system consists of two ImagerPro Plus digital CCD cameras and a double-pulsed Nd: YAG laser from Big Sky Laser. The system is controlled with DaVis 7.1 software. DaVis is a CCD image acquisition program developed by LaVision and controlled by a LaVision dual-processor Programmable Timing Unit (PTU). The PIV system cameras are mounted on a 3-directional traverse system that is controlled by three separate electric stepping motors. The cameras can be positioned and re-positioned to within 2 $\mu \mathrm{m}$ accuracy using linear stages and digital readouts at the operator's station. The spanwise laser position is also controlled with an electric stepping motor. The laser can be positioned to within $5 \mu \mathrm{m}$ accuracy with an optical linear stage on the laser and a digital readout located at the operator's station. The PIV system laser was mounted below the test section (Fig. 1) and produced a vertical light sheet approximately $2 \mathrm{~mm}$ thick. Both of the two PIV system cameras were mounted on one side of

\footnotetext{
* References herein to any specific commercial product, process, or service by trade name, trademark, manufacturer, or otherwise, does not necessarily constitute or imply its endorsement, recommendation, or favoring by the U.S. Government, any agency thereof, or any company affiliated with the Idaho National Laboratory.
}

the test section and aligned horizontally for camera views normal to the vertical light sheet.

\section{EXPERIMENTAL MODEL}

Fig. 2 is a picture of the experimental model that was installed in the MIR test section. The model is fabricated from fused

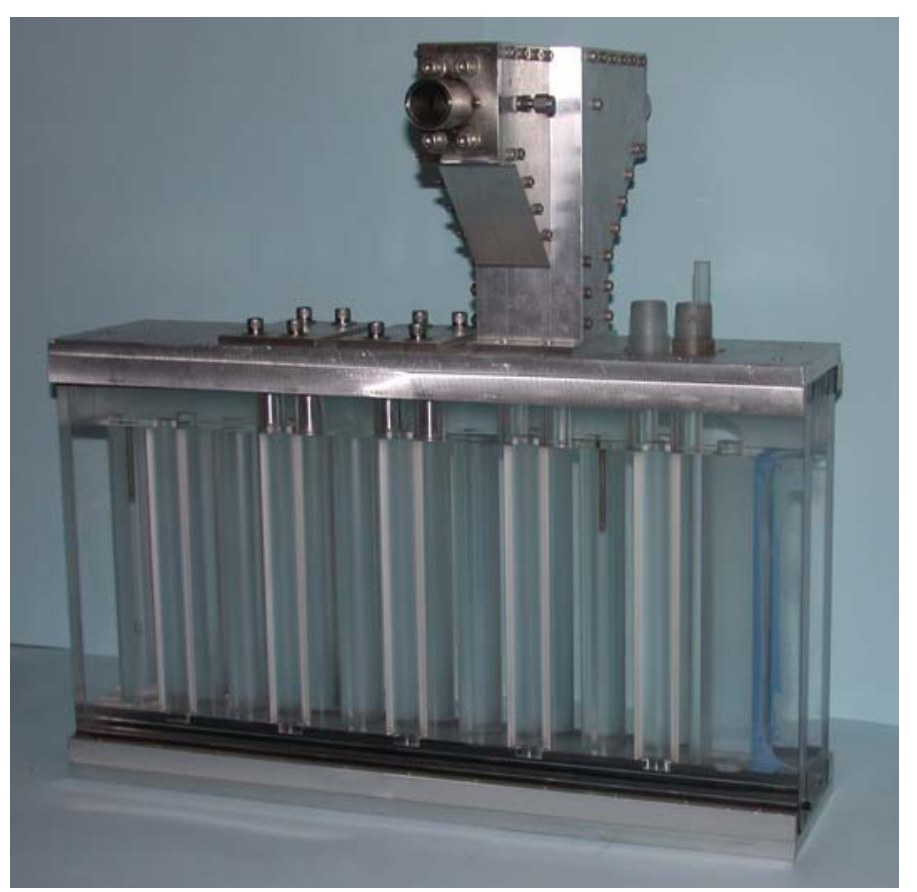

Figure 2. Quartz Model.

quartz and carefully positioned, located and fixed in the test section (see Appendix A by Condie et al. [6] for detailed drawings of the model). Table 1 lists some of the key parameters of the model. Mineral oil from the auxiliary loop enters into the model jets on the top of the model via four inlet jet elbow manifolds like the aluminum manifold shown in Fig. 2. The four inlet jet flows merge in the lower plenum and flow

Table 1. Model Parameters

\begin{tabular}{cc}
\hline Properties & Value \\
\hline Model length & $558.80 \mathrm{~mm}$ \\
Model height & $306.40 \mathrm{~mm}$ \\
Model width & $104.78 \mathrm{~mm}$ \\
Channel height & $217.50 \mathrm{~mm}$ \\
Channel width & $53.98 \mathrm{~mm}$ \\
Post diameter & $31.75 \mathrm{~mm}$ \\
Post height & $217.5 \mathrm{~mm}$ \\
Jet inlet diameter & $22.10 \mathrm{~mm}$ \\
Centerline distance between posts & $93.50 \mathrm{~mm}$ \\
Ratio of plenum height to post diameter & 6.85 \\
Ratio of jet diameter to post diameter & 0.7 \\
Ratio of channel width to post diameter & 1.7 \\
\hline
\end{tabular}


toward the outlet (left) end of the model where the flow exits and merges with the primary loop flow. The four jet inlet flows are conditioned in the elbow manifolds to model flow characteristics expected to be present in the actual GCR cooling channels that the inlet jets are simulating. Key requirements for the inlet-jet flows are that they are moderately turbulent, uniform and contain negligible swirl. When the working fluids reach the inlet jet elbow manifolds the flows are turned and straightened, then pass through a honeycomb, through a screen, and finally through a turbulence generator to induce expected levels of turbulence before entering the inlet jets.

\section{EXPERIMENTAL PROCEDURES}

The main circulating pump was operated at $50 \mathrm{rpm}$ to circulate the mineral oil around the exterior of the model at approximately $0.18 \mathrm{~m} / \mathrm{s}$ for index-matching temperature control. The temperatures of both the primary flow loop and auxiliary flow loop were controlled with LabVIEW ${ }^{\text {TM }}$ software. The temperature control system maintained the oil temperature to within $\pm 0.05{ }^{\circ} \mathrm{C}$ of the calculated index-matching temperature $\left(\sim 23.3{ }^{\circ} \mathrm{C}\right)$ in the model and to within $\pm 0.03{ }^{0} \mathrm{C}$ of the index-matching temperature in the primary flow loop. The facility remained at a constant, steady state condition throughout the data collection periods. Temperature records for all data collection files are archived on the temperature control computer. The PIV system was operated in the 3-D, Expert User mode. Laser power, Q-Switch delays, and the time between frames of the double-image cameras (dt) were adjusted using the Interactive Mode in the DaVis 3-D PIV software.

In an effort to balance the requirement for high resolution data and to keep the size of data files within reasonable limits (for data processing and data storage considerations), the collection effort on the model was divided into eight regions. The lower plenum area of the model was divided into six regions and, for the higher $\mathrm{Re}_{\text {Jet }}$ flow study, the inlet jet area was divided into two regions (one region for jets 1 and 2 and one region for jets 3 and 4). Additionally, in order to collect (3D) data across the entire width of the model channel (spanwise) the laser and cameras were positioned at 23 different spanwise planes. The laser-light sheet was adjusted to a thickness of about $2 \mathrm{~mm}$ which allowed for complete coverage of the model except for an area near the model walls where the laser-light sheet was blocked by O-ring seals. Therefore, each region of the lower plenum consisted of 23 PIV image files-one file for each spanwise plane. The inlet-jet regions only required 11 planes/files to cover the full width of the jets.

Because of the refractive index difference between the air space where the cameras operated and the mineral oil where the light sheet was located, it was necessary to coordinate the movement of the two digital cameras relative to the movement of the laser-light sheet. This coordination was accomplished with a MATHCAD code. The code used the mineral oil temperature to determine the index of refraction of the mineral oil and the camera angles relative to the laser-light sheet reported by the camera calibration procedure to calculate a movement ratio for the camera movement relative to the laser light sheet movement. This ratio was typically between 0.62 and 0.68 , that is, for a movement ratio of 0.66 , a $2 \mathrm{~mm}$ shift of the laser-light sheet required the camera support to be moved about $1.32 \mathrm{~mm}$.

Table 2 summarizes the settings used on the MIR and PIV systems.

Table 2. MIR and PIV Parameters

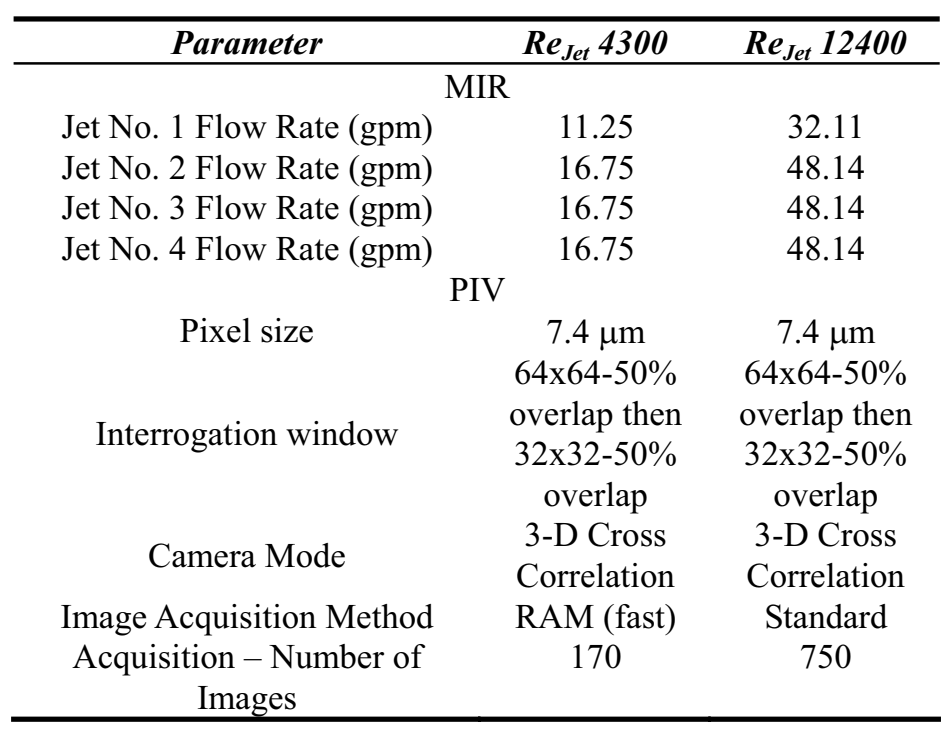

Data post-processing of the acquired images was accomplished with DaVis 7.1 software. The post-processed data were then transferred from DaVis to a secondary PC where data were organized and displayed with TecPlot $360^{\mathrm{TM}}$ and/or MS Excel software. The total processing time exceeded 900 hours of computer time and produced approximately 2 TB of data.

\section{UNCERTAINTY ESTIMATES}

The objective of uncertainty analysis is to develop an understanding of the estimated experimental uncertainties in the results. For proper benchmark databases, the experimental uncertainties of all measured quantities and their propagation into the results must be obtained quantitatively. In a complicated experiment such as this, some experimental uncertainties can be expected to vary significantly with position as the local velocities vary. McEligot et al. [9] presents a detailed analysis of the experimental uncertainty estimates for this study. Table 3 is a list of some of the uncertainty estimates.

Table 3. Uncertainty Estimates

\begin{tabular}{cccc}
\hline Parameter & Uncertainty & Parameter & Uncertainty \\
\hline Pixel & 0.3 pixels & Image & $\pm 0.16 \mathrm{~mm}$ \\
displacement & $\sim 0.001 \%$ & Fistance & $\pm 0.05^{\circ} \mathrm{C}$ \\
Timing & & &
\end{tabular}




\begin{tabular}{cccc}
\hline Lightsheet & \multicolumn{3}{c}{ temperature } \\
thickness & $10 \%$ & Fluid density & $\sim 0.2 \%$ \\
Velocity & $\sim 0.3 \%-$ & $\begin{array}{c}\text { Dynamic } \\
\text { viscosity }\end{array}$ & $\sim 2 \%$ \\
$\begin{array}{c}\text { Turbulence } \\
\text { intensity }\end{array}$ & $\sim 1.2 \%$ & $\begin{array}{c}\text { Kinematic } \\
\text { viscosity }\end{array}$ & $\sim 0.2 \%$ \\
$\begin{array}{c}\text { Scatter in } \\
\text { velocity }\end{array}$ & $\sim 0.4 \%-10 \%$ & $\begin{array}{c}\text { Refractive } \\
\text { index }\end{array}$ & $\sim 0.02 \%$ \\
statistics & Mean square \\
fluctuations & $\sim 1.3 \%-6 \%$ & Geometry & $\sim 0.2 \%$ \\
$\begin{array}{c}\text { Camera } \\
\text { position } \\
\text { Laser }\end{array}$ & $\pm 2 \mu \mathrm{m}$ & Flow rates & $0.5 \%$ \\
position & $\pm 5 \mu \mathrm{m}$ & $\begin{array}{c}\text { Reynolds } \\
\text { numbers }\end{array}$ & $1 \%$ \\
\hline
\end{tabular}

\section{EXPERIMENTAL RESULTS}

The objective of the experimental program was to obtain velocity field measurements for CFD code assessment. To accomplish this objective the flow inside the lower plenum model was characterized with velocity-vector fields and fourteen scalar quantities. McIlroy et al. [10] provides a list that defines the vector and scalar field measurements that were obtained.

Since uniform time intervals were employed, the time-mean statistics are calculated from suitable arithmetic averages of the stored data.

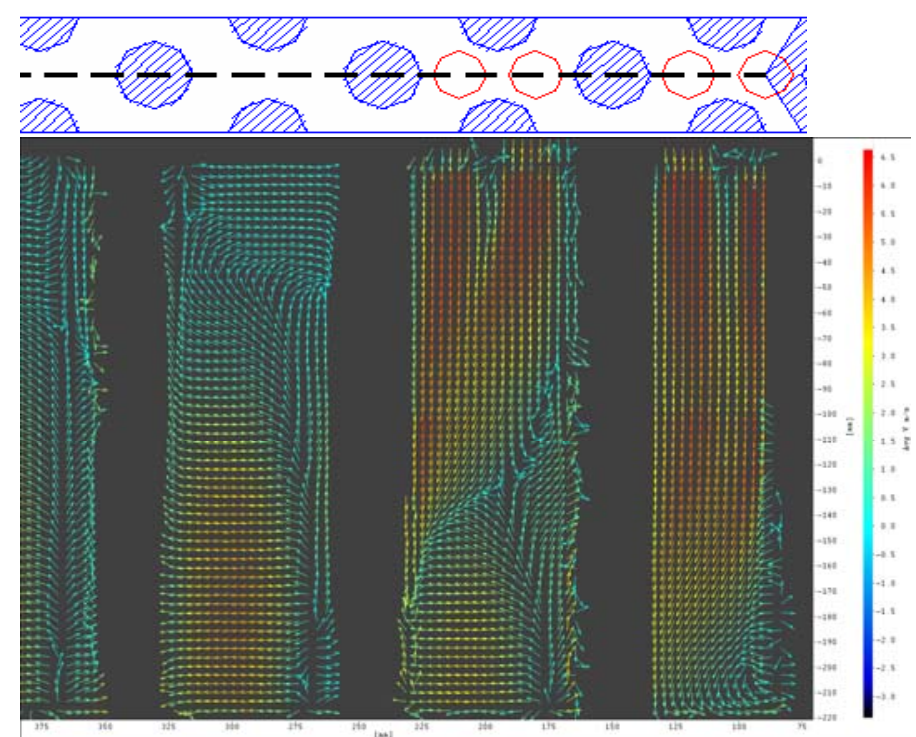

Figure 3. Mean Vector Field for $\operatorname{Re}_{\text {Jet }} \sim 12400$

The data set presented here is a sample of the data available for code assessment. Due to the tremendous volume of data obtained and the complicated nature of the flow, only a brief analysis is presented. Data at specific locations will be presented along with a brief description of some of the major phenomena observed in the flow.

Figure 3 is a vector plot of the flow along the centerline of the model. The black regions between the vector groups represent the model support posts. Flow enters the model vertically from the four inlet jets located at the top-right corner of the plot and streams downward into the lower plenum where it interacts with the support posts and reflector wall, and then gradually turns toward the left and flows toward the model exit located to the left of the figure.

The dashed line in the diagram above the figure shows the location of this data plane.

Figure 4 is a streamline plot of this flow.

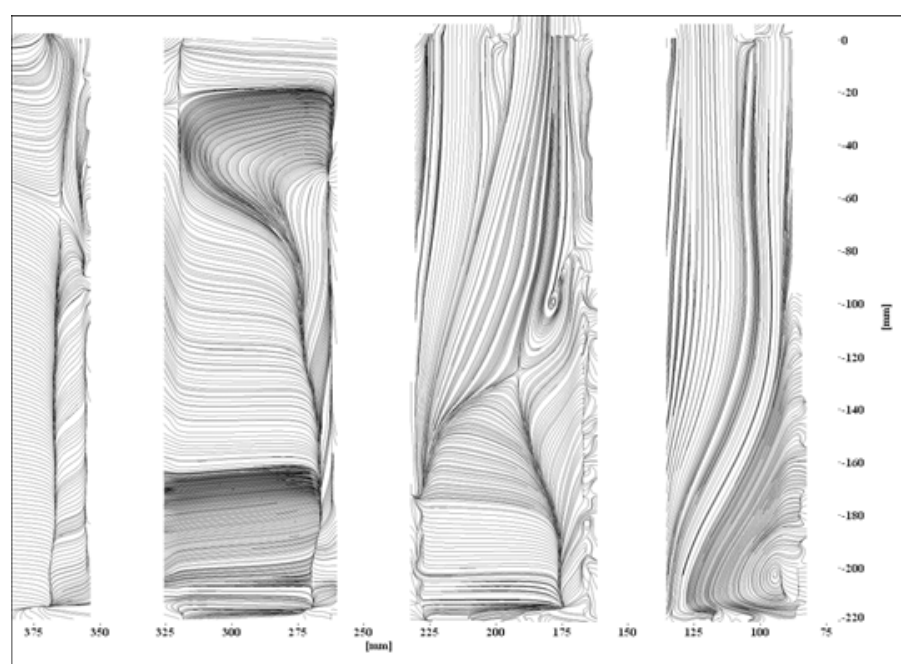

Figure 4. Mean Streamlines for $\operatorname{Re}_{\mathrm{Jet}} \sim 12400$

Three major structures are visible in Figures 3 and 4: the recirculation zone in the lower right corner, the recirculation zone near the mid-height of the model between the first two support posts, and the recirculation zone near the top of the model on the downstream side of the second and third support posts. Three secondary structures are also visible: the line of merging flow below the two downstream (left) pair of jets and just downstream of the first support post from the bottom of the model to just below the second recirculation zone noted above, the line of merging flow just downstream of the second support post, and the line of merging flow that extends along the full model height on the downstream side of the third support post.

The first recirculation zone is formed by the first pair of inlet jets and their interaction with the reflector wall, first support post, and the bottom of the model. The flows from the two jets merge quickly near the top of the model and are channeled downward between the first support post and reflector wall. As the flow approaches the bottom of the plenum the major portion of this flow turns to the left, flows around the first support post, and interacts with the flow from the second pair of jets. A small portion of this flow is forced to the right where it encounters the reflector wall and creates a recirculation zone. Some of this recirculating fluid is forced up the reflector wall where it interacts with the downward flow 
from the jets and is subsequently reversed and forced toward the bottom of model plenum.

The second major structure is the recirculation zone that is formed by the flow from the second pair of jets. These flows also merge near the top of the plenum and are channeled downward in the area between the first and second support posts where they interact with the flow from the first (upstream) pair of jets that has passed around the first support post. This interaction results in a portion of the flow rising up the downstream edge of the first support post, causing a second recirculation zone about half way up the downstream edge of the first support post. The remainder of the flow generates a wake behind the lower portion of the second support post and then begins to flow toward the model exit (toward the left).

The third major structure is formed as the flows from both jet pairs merge and begin to flow toward the exit and interact with the second support post. Because no fluid is entering the plenum downstream of the second support post (no inlet jets above this region which corresponds to the central section of an annular core/plenum), the fluid flows around the second post, forms a wake and begins to rise to fill the upper portion of the model. A portion of this flow near the top of the plenum is moves to the right on the downstream side of the second support post, and then downward forming the third recirculation zone. The flows in the bottom half of the model on the downstream side of the second support post merge and move toward the model exit. The flow then moves around the third support post, merges in a wake on the downstream side of the post, and gradually flows toward the left and slightly upward as it moves toward the model exit.

Finally, a small recirculation zone is evident on the downstream side of the third support post. This flow appears to be a result of the recirculating flow on the upstream side of the post. On the downstream side of the post the upper portion of the flow moves downward until it joins the flow moving upward from the bottom of the model. These two flows merge and move around the post where they join the recirculation zone between the second and third posts.

Figure 5 displays values of average (mean) Vy (vertical velocity component) of a vertical data slice along the centerline of the model in the regions below the four inlet jets. The small diagram above the figure describes the spanwise location of the data slice. At the $y \sim-70 \mathrm{~mm}$ depth, the vertical velocity under the jets (vertical momentum with no imposed crossflow) is substantial and downward. Lower in the plenum (at $\mathrm{y} \sim-150$ $\mathrm{mm}$ ), the flow under the jets in the $\mathrm{Re}_{\mathrm{Jet}} 4300$ case has reversed (flows upward) and the flow in the $\operatorname{Re}_{\text {Jet }} 12400$ case shows a flow reversal (upward flow) under jets 3 and 4.
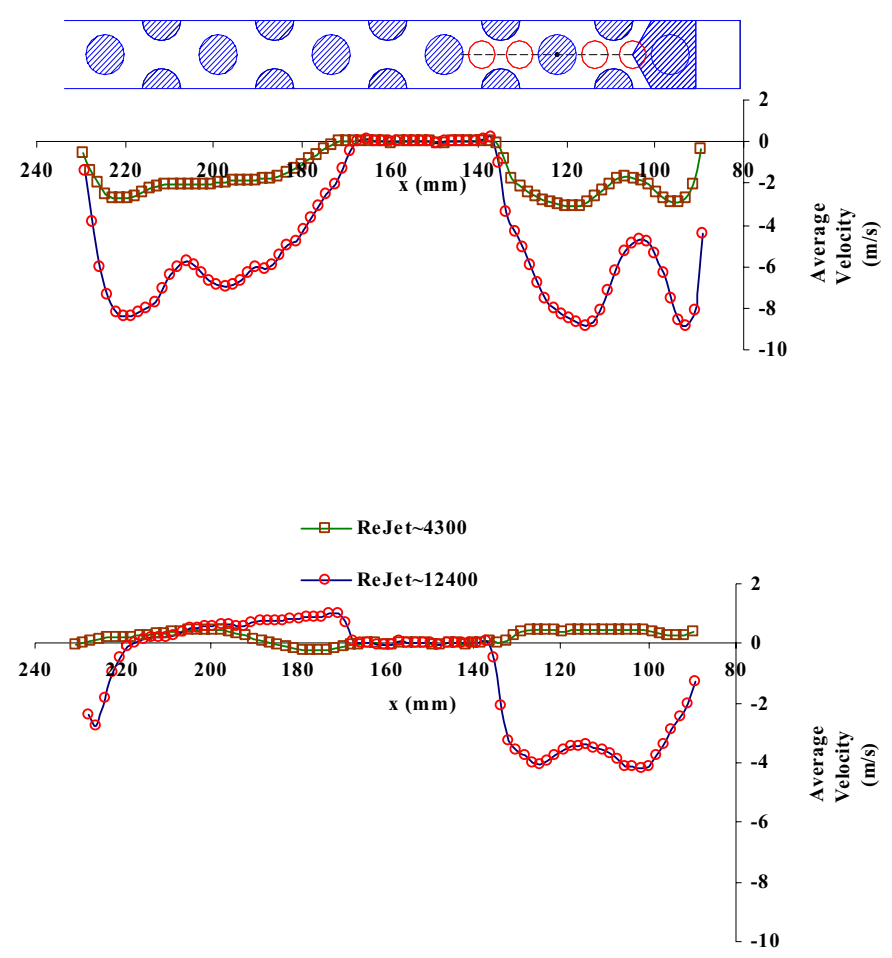

Figure 5. Average $V y$ at y $\sim-70 \mathrm{~mm}$ (top) and y $\sim-150 \mathrm{~mm}$ (bottom)
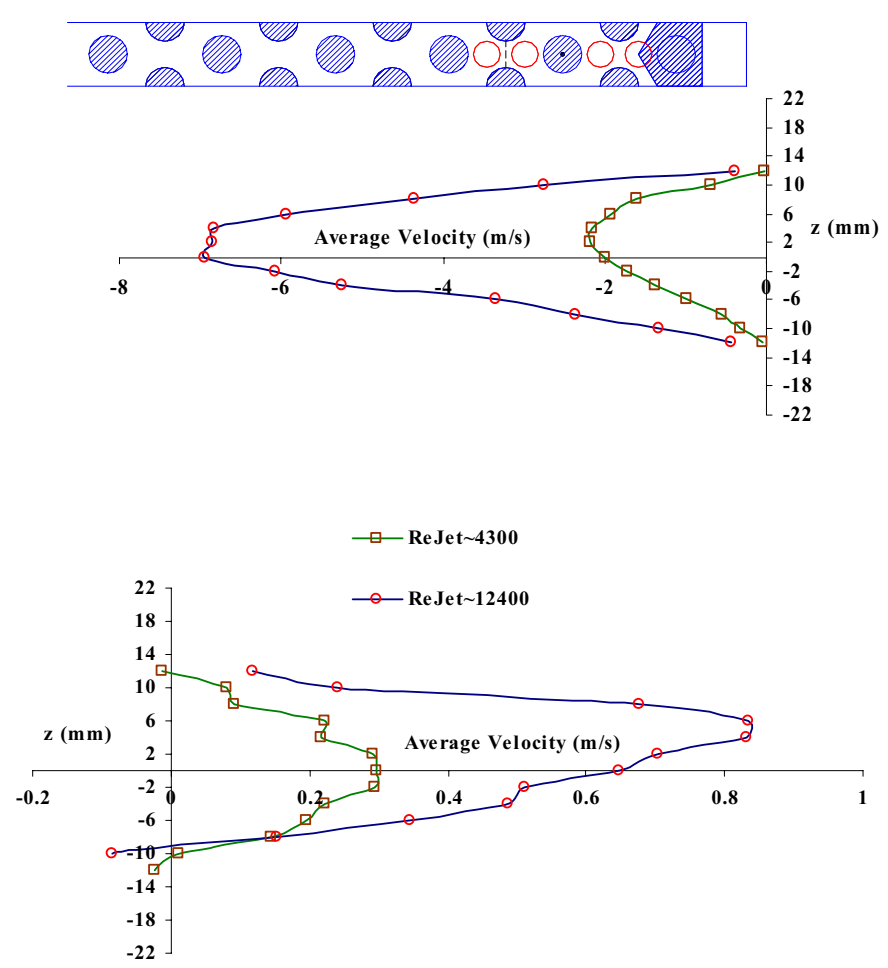

Figure 6. Average Vy at $\mathrm{y} \sim-70 \mathrm{~mm}$ (top) and $\mathrm{y} \sim-150 \mathrm{~mm}$ (bottom) 
Figure 6 displays values of average (mean) Vy (vertical velocity component) in a spanwise line from the vertical data slice as shown in the diagram above the figure. At $\mathrm{y} \sim-70 \mathrm{~mm}$ depth, the vertical velocity is substantial and negative (downward) from the inlet-jet flows entering the lower plenum from jets 3 and 4 . Lower in the plenum (at $y \sim-150$ ), the vertical flow reverses and moves upward to form the lower part of a recirculation zone noted earlier.

Figure 7 displays the inlet jet average (mean) Vy (vertical) velocity profiles for the $\mathrm{Re}_{\text {Jet }} 12400$ case. The dashed lines represent the locations of the inlet jets. Jet No. 1 is on the left, inlet jets 2, 3, and 4 are to the right. The profiles were measured at a level inside the inlet ducts $11 \mathrm{~mm}$ above the

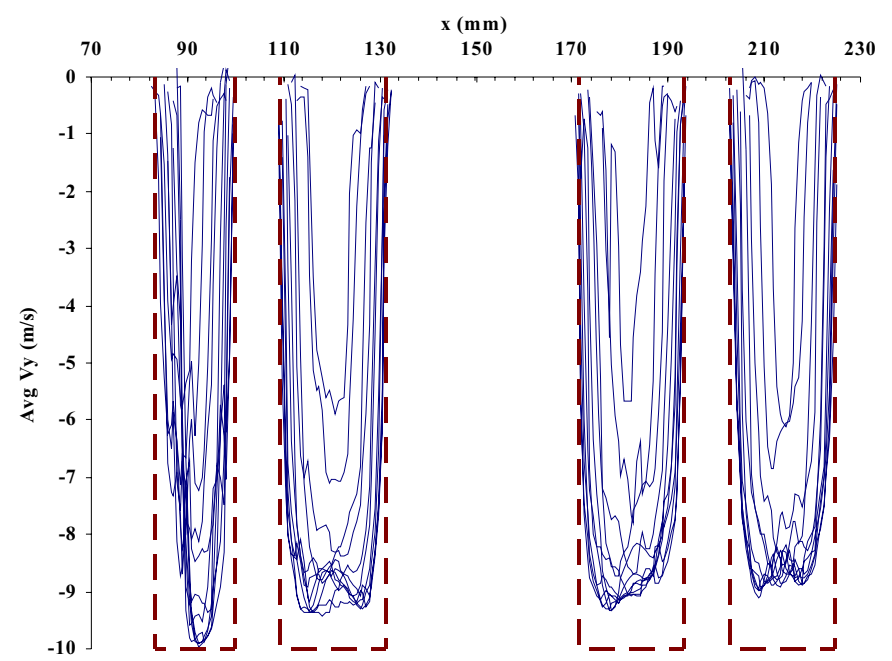

Figure 7. Average $V y$ in inlet jets for $\operatorname{Re}_{\mathrm{Jet}} \sim 12400$ at $y \sim 11$, $-10<z<+10 @ 2$ mm intervals

opening into the plenum $\left(\mathrm{y} / \mathrm{d}_{\text {Jet }} \sim 0.5\right.$ to the exit plane). The eleven velocity profiles in each inlet jet display developing, non-uniform, turbulent flow in the ducts. Jet No. 1 is smaller than the other jets because $1 / 3$ of this jet is filled, as in a prismatic reactor, by the reflector wall model. These profiles were extracted from the raw data files using the locations of the jets from fabrication drawings and analysis of the flows close to the jet walls. It is noteworthy that results of numerical integrations using both the Trapezoid Rule and Simpson's Rule produce an inlet volume flow rate of $169.68 \mathrm{gpm}$ - which is only $3.9 \%$ less than the volume flow rate measured by calibrated flow meters upstream of the jets. The estimated uncertainty in the measured flow rate is approximately $1 \%$ and the estimated uncertainty in the integrated flow rate is approximately $0.4 \%$ to $1.2 \%$.

\section{STANDARD PROBLEM}

A challenge of designing and licensing the VHTR is to confirm that the intended analysis tools can be used confidently to make decisions and to assure that the reactor systems are safe and meet the performance objectives of the Generation IV
Program. The research and development projects at INL will ensure that the tools used to perform the required calculations and analyses are accurate and reliable.

CFD analyses will be a major component in the analysis suite that will be required to design and license the VHTR so the reactor can operate at maximum outlet temperatures and efficiencies. Only CFD analysis tools have the capability to determine where localized hot spots will occur in the reactor and also whether or not unacceptably large thermal gradients are present.

The calculational envelope of the CFD tools used to analyze the behavior of the VHTR is defined by the scenarios and phenomena that these tools can calculate with confidence. CFD tools can only be used confidently when the results they produce have been shown to be in reasonable agreement with first-principle results, thought-problems, and data that describe the "highly ranked" phenomena inherent in all operational conditions and important accident scenarios for the VHTR. Reasonable agreement is achieved when the calculation generally lies within the uncertainty band of the data used for validation and always shows the same trends as the data and when code deficiencies are minor.

Presently, the CFD tools to be used for analyzing the VHTR are not ready to perform design and analysis, nor are they ready for licensing calculations to the standard that will be required by the VHTR. Considerable validation and, perhaps, development of the software tools is required. Additionally, practices and procedures are required for both validating and developing the necessary CFD software that are acceptable to the nuclear community.

The validation process is based on developing a set of standard problems that will populate a validation matrix for the various tools. The standard problems are defined by the Generation IV International Forum Standard Problem Committee, which defines its standard problems on the basis of comprehensive phenomena identification and ranking tables (PIRT) [11]. The standard problems, which are defined using high-quality data sets with known uncertainty bands, are the measures used to determine whether or not an analysis tool is capable of calculating the required phenomena. The members of the Standard Problem Committee are experts in the potential scenarios that are projected to be important in the VHTR.

The standard problems are passed to the Problem Oversight Committee. Members of this committee are experts in using and validating the analysis tools. Some members of this committee were specifically chosen due to their expertise in other industries where CFD is widely used. This committee defines the practices and procedures that must be used to perform the standard problems, and they also distribute the standard problem to the participants. Finally, the Problem Oversight Committee is responsible for coordinating the comparisons between the participants' solutions and the experimental results, including the evaluation of the validation. It is understood that many of the standard problem's calculations will be "blind", that is, the participants will not be 
privy to the experimental data while their calculation is in progress.

Standard problems form the basis for determining whether a software tool is capable of analyzing the behavior of a reactor system undergoing a review for an operating license. The term "standard problem" stems from the use of the data sets that make up these problems as a measure (hence, a standard) to determine the acceptability of the software.

Standard problems consist of data sets that have the following characteristics:

a. The data set describes a phenomenon, or a set of phenomena, that influences the behavior of an important figure-of-merit. That is, given that the figure-of-merit is the reactor vessel wall temperature, which must be less than a predetermined value, then important phenomena are those that significantly influence the reactor vessel wall temperature. Such phenomena are identified in phenomena identification and ranking studies and are documented [11]. An example of such a phenomenon is the turbulent mixing of hot exit gases in the lower plenum of the reactor vessel because hot jets with an above-average temperature may impinge on the outlet plenum wall and perhaps cause a local hot spot on the reactor-vessel wall.

b. The phenomenon given in the standard problem data set, although it may be measured in a reduced-scale system, can be scaled to the full-sized system using accepted scaling practices. The scaling studies that link the experimental apparatus and data to the full-sized system are documented in a report.

c. The standard problem data set has been shown to measure the data required to determine whether the software are capable of calculating the important phenomenon.

d. The standard problem data set has uncertainties associated with each data point.

e. The quality assurance procedures used to design the experiment, build the experiment, and conduct the experiment are consistent with NQA-1 requirements.

The experiment and results summarized in this paper are intended to assess CFD software and the experiment described herein meets the requirements identified in subparagraphs $\mathrm{a}-\mathrm{e}$ above.

\section{CONCLUDING REMARKS}

The model design and MIR flow facility produced satisfactory flow conditions, as required by previous scaling studies and model design. As a result of the experiments described in this paper, the objectives of developing benchmark databases for the assessment of CFD solutions of the momentum equations, scalar mixing and turbulence models for typical prismatic VHTR plenum geometries in the limiting case of negligible buoyancy and constant fluid properties have been met. Additionally, the data obtained from these experiments meet the requirements of a standard problem as defined.

Preliminary measurements of velocity components have been compiled for a low-power case of $\operatorname{Re}_{\text {Jet }} \sim 4300$, and detailed measurements of the flow field for the maximum achievable flow rate in the present MIR Flow facility of $\mathrm{Re}_{\mathrm{Jet}} \sim$ 12400 have also been completed. The data have been documented to identify and report estimated uncertainties of the measurements and have been collected into various formats suitable for release to the CFD community and others, as necessary. Future plans include distribution of instructions to obtain data sets and points of contact at INL.

\section{ACKNOWLEDGMENTS}

This manuscript has been authored by a contractor of the U.S. Government under DOE Contract DE-AC07-05ID14517. Accordingly, the U.S. Government retains a nonexclusive, royalty-free license to publish or reproduce the published form of this contribution, or allow others to do so, for U.S. Government purposes.

The authors also acknowledge the highly professional and timely support and assistance of Dr. Steven L. Anderson of LaVision, Inc., Professor Barton L. Smith of Utah State University, and Richard R. Schultz of INL for their assistance in this project.

\section{REFERENCES}

[1] Mikielewicz, D. P., Shehata, A. M., Jackson, J. D., and McEligot, D. M., 2002, “Temperature, Velocity and Mean Turbulence Structure in Strongly-Heated Internal Gas Flows. Comparison of Numerical Predictions with Data," Int. J. Heat Mass Transfer, 45, pp. 4333-4352.

[2] Richards, A. H., Spall, R. E., and McEligot, D. M., 2004, "An Assessment of Turbulence Models for Strongly Heated Internal Gas Flows," Proceedings of the Fifteenth IASTED International Conference on Modeling and Simulation Conference, Marina Del Ray, CA., 1-3 March 2004, pp. 119-124.

[3] McEligot, D. M., Condie, K. G., McCreery, G. E., McIlroy, H. M., Pink, R. J., Hochreiter, L. E., Jackson, J. D., Pletcher, R. H., Smith, B. L., Vukoslavcevic, P., Wallace, J. M., Yoo, J. Y., Lee, J. S., Ro, S. T., and Park, S. O., 2005, "Advanced Computational Thermal Physics (CTFP) and its Assessment for Light Water Reactors and Supercritical Reactors," INEEL Technical Report INEEL/EXT-05-00901.

[4] MacDonald, P. E., Sterbentz, J. W., Sant, R. L., Bayless, P. D., Schultz, R. R., Gougar, H. D., Moore, R. L., Ougouag, A. M., and Terry, W. K., 2003, "NGNP Preliminary Point Design - Results of the Initial Neutronics and ThermalHydraulic Assessments, INEEL Technical Report INEEL/EXT-03-00870, Rev. 1.

[5] McEligot, D. M., and McCreery, G. E., 2004, "Scaling Studies and Conceptual Experiment Designs for NGNP CFD Assessment," INL External Report INEEL/EXT-0402502 (30 November 2004).

[6] Condie, K. G., McCreery, G. E., McIlroy Jr., H. M., and McEligot, D. M., 2005, "Development of an Experiment 
for Measuring Flow Phenomena Occurring in a Lower Plenum for VHTR CFD Assessment," INL External Report INL/EXT-05-00603 (21 September 2005).

[7] Roach, P. J., 1998, Verification and Validation in Computational Science and Engineering, Hermosa, Albuquerque, NM, p 271.

[8] Stoots, C., Becker, S., Condie, K., Durst, F., and McEligot, D. M., 2001, "A Large-Scale Matched Index of Refraction Flow Facility for LDA Studies Around Complex Geometries," Exp. in Fluids, 30, pp. 391-394.

[9] McEligot. D. M., McIlroy, H. M. Jr., and Johnson, R. C., 2007, "Estimated Uncertainties in the Idaho National Laboratory Matched-Index-of-Refraction Lower Plenum Experiment," INL External Report INL/EXT-07-13539, pp. 8-14 (November, 2007).

[10] McIlroy, H. M. Jr., McEligot, D. M., and Pink, R. J., 2007, "Measurement of Turbulent Flow Phenomena for the Lower Plenum of a Prismatic Gas-Cooled Reactor," Proceedings, $12^{\text {th }}$ International Meeting on Nuclear Reactor Thermal Hydraulics, September 30 - October 4, 2007, Pittsburgh, PA, Log No. 67.

[11]Lee, W-J., Kim, K-D., Hwang, M-K., Lim, H-S., Lee, SW., Wei, T. Y. C., Vilim, R. B., Feldman, E. E., Pointer, W. D. R., Schultz, R. R., Bayless, P. D., and Moore, R. L., 2005, "Generation of a Preliminary PIRT (Phenomena Identification and Ranking Table) for Very High Temperature Gas-Cooled Reactors," KAERI/TR3050/2005, INL/EXT-05-00829, or ANL-GenIV-066 (September 2005). 